\title{
GAMBARAN PENGETAHUAN WANITA USIA SUBUR TENTANG PENCEGAHAN KANKER PAYUDARA DI PUSKESMAS MACCINI SAWAH MAKASSAR 2019
}

\author{
*)Rukinah \\ *)Akademi Kebidanan Sandi Karsa Makassar \\ *)Program Studi D-III Kebidanan Sandi Karsa Makassar
}

\begin{abstract}
ABSTRAK
Telah dilakukan penelitian tentang Gambaran Pengetahuan Wanita Usia Subur Tentang Pencegahan Kanker Payudara di Puskesmas Maccini Sawah Makassar. Jenis penelitian yang digunakan adalah jenis deskriptif. Populasi adalah seluruh wanita usia subur yang ada diwilayah kerja Puskesmas Maccini Sawah. Sampel adalah yang memenuhi kriteria inklusi subjek yaitu penelitian dapat mewakili sampel penelitian yang memenuhi syarat sebagai sampel, sedangkan kriteria eksklusi yaitu subjek penelitian tidak dapat mewakili sampel karena tidak memenuhi syarat sebagai sampel penelitian. Hasil penelitian menunjukkan bahwa pengetahuan wanita usia subur tentang pengertian kanker payudara terdapat 68 orang $(68 \%)$ yang tahu dan 32 orang (32\%) yang tidak tahu. Pengetahuan tentang faktor resiko kanker payudara hanya 43 orang $(43 \%)$ yang tahu dan 57 orang $(57 \%)$ yang tidak tahu. Pengetahuan tentang gejala kanker payudara hanya 64 orang (64\%) yang tahu dan 36 orang (36\%) yang tidak tahu. Pengetahuan tentang pencegahan kanker payudara hanya 74 orang (74\%) yang tahu dan 26 orang $(26 \%)$ yang tidak tahu. Pengetahun tentang pemeriksaan payudara sendiri hanya 55 orang $(55 \%)$ yang tahu dan 45 orang $(45 \%)$ yang tidak tahu. Kesimpulan hasil penelitian dari 100 responden menunjukkan bahwa pengetahuan wanita usia subur tentang pengertian kanker payudara, gejala kanker payudara, pencegahan kanker payudara, pemeriksaan payudara sendiri di Puskesmas Maccini Sawah Makassar kualitasnya baik dan faktor resiko kanker kualitasnya kurang baik.
\end{abstract}

Kata kunci: Pengetahuan, Kanker Payudara

\section{PENDAHULUAN}

\section{A. Latar Belakang}

Kanker payudara merupakan kanker pembunuh nomor 2 setelah kanker leher rahim. Sel kanker payudara yang pertama dapat tumbuh menjadi tumor sebesar $1 \mathrm{~cm}$ pada waktu 8-12 tahun. Sel kanker tersebut diam pada kelenjar payudara. Selsel kanker payudara ini dapat menyebar melalui aliran darah ke seluruh tubuh. Kapan penyebaran itu berlangsung, kita tidak tahu. Sel kanker payudara dapat bersembunyi di dalam tubuh kita selama bertahun-tahun tanpa kita ketahui, dan tibatiba aktif menjadi tumor ganas atau kanker.

Data WHO menunjukkan bahwa $78 \%$ kanker payudara terjadi pada wanita usia 50 tahun. Hanya $6 \%$-nya terjadi pada mereka yang berusia kurang dari 40 tahun. Meski demikian, kian hari makin banyak penderita kanker payudara yang berusia 30an. Setiap tahun lebih dari 580.000 kasus baru ditemukan diberbagai Negara berkembang dan kurang lebih 372.000 pasien meninggal karena penyakit kanker. Tapi sampai saat ini penyebab kanker payudara belum diketahui secara pasti.

Menurut WHO 8-9\% wanita akan mengalami kanker payudara. Ini menjadikan kanker payudara sebagai jenis kanker yang paling banyak ditemui para wanita. Setiap tahun lebih dari 250.000 kasus baru kanker payudara terdiagnosa di Eropa dan kurang lebih 175,000 di Amerika Serikat. Kanker payudara merupakan penyebab utama kematian pada wanita akibat kanker. Setiap tahunnya, di Amerika Serikat 44,000 pasien meninggal karena penyakit ini sedangkan di Eropa lebih dari 165,000 setelah perawatan, sekitar $50 \%$ akhir dan hanya bertahan hidup 18-30 bulan.

Insiden tertinggi ditemukan pada beberapa daerah di Amerika Serikat mencapai di atas 100/ 100.000; berarti ditemukan lebih 100 penderita dari 100.000 orang. Kemudian diikuti dengan beberapa negara Eropa Barat tertinggi Swiss 73,5/100.000. Untuk Asia masih berkisar antara 10-20/100.000 seperti daerah tertentu di Jepang 17,6/100.000; Kuwait 17,2/100.000; dan Cina 9.5/100.000. (Th. Endang Purwoastuti, 2009, hal 14)

Pada tahun 2008, the American Cancer Society (ACS) memperkirakan setiap tahunnya sekitar 178,00 perempuan akan terdiagnosis kanker payudara. Jumlah ini ditambah dengan 2 juta perempuan yang memiliki riwayat ini (Heru Purnomo, 2009, hal 91).

Di Indonesia, berdasarkan Patological based Registration atau berdasarkan pencatatan pemeriksaan jaringan, kanker payudara mempunyai angka kejadian relatif $11,5 \%$, diperkirakan di Indonesia mempunyai angka kejadian minimal 20 ribu kasus baru pertahun, dengan kenyataan $50 \%$ kasus baru ditemukan pada keadaan stadium lanjut. Sebagai perbandingan angka kejadian kanker payudara di Amerika Serikat, dari 100 ribu wanita 
didapatkan 92 wanita menderita kanker payudara pertahun. Dengan angka kematian 27 orang dari 100 ribu penderita, atau $80 \%$ dari kematian yang dijumpai pada wanita.

Data Dinas Kesehatan Provinsi Sulawesi Selatan menyebutkan kanker yang paling banyak menyerang masyarakat adalah kanker payudara. Seperti yang kita lihat dari kasus kanker payudara pada tahun 2016 yang tercatat sebanyak 203 kasus di Rumah Sakit, dan 316 di Puskesmas. Sedangkan pada tahun 2017 jumlah kasus kanker payudara meningkat yaitu 252 di Rumah Sakit dan 600 di Puskesmas (Data dinkes 2016 dan 2017).

Pemeriksaan kanker payudara sendiri telah dianjurkan oleh Amerikan Cancer Society dan organisasi lain selama berpuluh-puluh tahun. Sebelum penggunaan mammografi penyaring secara luas sekitar $90 \%$ kanker payudara ditemukan oleh wanita itu sendiri. Tetapi tidak ada bukti yang menguatkan bahwa pendekatan pemeriksaan payudara sendiri menurunkan mortalitas dari kanker payudara. Namun demikian akal sehat mengharuskan bahwa seorang wanita harus mengenali dan melaporkan setiap perubahan yang ditemukan oleh dirinya sendiri. Satu kelemahan utama teknik ini adalah kepatuhannya yang rendah hanya sekitar $25 \%$ wanita secara teratur melakukan pemeriksaan payudara sendiri (Eni Setiati, 2009, hal 42).

Indonesia sudah cukup lama mengampanyekan SADARI (pemeriksaan payudara sendiri). SADARI adalah tingkat deteksi dini terhadap gejala-gejala kanker payudara. Metode ini sangat sederhana, namun diharapkan dapat menekan tingginya angka penderita kanker payudara, karena semakin awal terdeteksi maka semakin cepat proses pengobatan yang diperlukan.

Padahal meski mendapat dukungan berupa layanan terbaik dan adanya kemajuan dalam ilmu kedokteran namun perjuangan melawan kanker payudara tidak selalu berhasil. Terbatasnya kemampuan manusia untuk mencegah kanker payudara maka diagnosis dini dan deteksi awal merupakan hal terpenting dalam pencegahan kanker payudara.

\section{B. Rumusan Masalah}

1. Bagaimana gambaran pengetahuan wanita usia subur tentang pengertian kanker payudara?

2. Bagaimana gambaran pengetahuan wanita usia subur tentang resiko kanker payudara?

3. Bagaiman gambaran pengetahuan wanita usia subur tentang gejala kanker payudara?

4. Bagaimana gambaran pengetahuan wanita usia subur tentang pencegahan kanker payudara?

5. Bagaimana gambaran pengetahuan wanita usia subur tentang pemeriksaan payudara sendiri (SADARI)?

\section{Tujuan Penelitian}

1. Tujuan umum

Untuk mengetahui gambaran pengetahuan wanita usia subur tentang pencegahan kanker.

2. Tujuan khusus

a. Untuk mengetahui tingkat pengetahuan wanita usia subur tentang pengertian kanker payudara

b. Untuk mengetahui tingkat pengetahuan wanita usia subur tentang resiko kanker payudara.

c. Untuk mengetahui tingkat pengetahuan wanita usia subur tentang gejala klinik kanker payudara.

d. Untuk mengetahui tingkat pengetahuan wanita usia subur tentang pencegahan kanker payudara

e. Untuk mengetahui tingkat pengetahuan wanita usia subur tentang pemeriksaan payudara sendiri (SADARI)

\section{Manfaat Penelitian}

1. Manfaat institusi

a. Sebagai bahan masukan bagi instansi terkait dalam rangka evaluasi dan kebijakan program kesehatan selanjutnya.

b. Menambah pengetahuan subjek tentang kanker payudara dan pencegahan dininya.

2. Manfaat ilmiah

Menambah sumber informasi dan merupakan bahan acuan bagi peneliti selanjutnya.

3. Manfaat praktis

Sebagai sumber informasi bagi penentu kebijakan dan pelaksanaan program di Puskesmas Maccini Sawah tentang pencegahan kanker payudara.

4. Manfaat peneliti

Pengalaman yang berharga bagi peneliti dalam memperluas wawasan dan pengetahuan mengenai pencegahan kanker payudara.

\section{METODE PENELITIAN}

\section{A. Jenis Penelitian}

Jenis penelitian yang digunakan adalah jenis deskriptif yaitu suatu metode penelitian yang bertujuan untuk membuat deskripsi atau gambaran tentang suatu keadaan secara objektif mengenai pengetahuan wanita usia subur tentang pencegahan kanker payudara di Puskesmas Maccini Sawah Makassar (A. Aziz Alimul Hidayat, 2009, hal 51).

\section{B. Waktu dan Tempat Penelitian}

Penelitian ini dilaksanakan pada bulan Maret 2019 di Puskesmas Maccini Sawah yang 
bertempat di jalan Maccini kecamatan Makassar, dengan batas-batas sebagai berikut:

a. Sebelah utara berbatasan dengan kelurahan Wajo Baru dan Malimongan Baru

b. Sebelah timur berbatasan dengan kelurahan Bara-Baraya Utara dan Merdekaya Utara

c. Sebelah selatan berbatasan dengan kelurahan Barana

d. Sebelah utara berbatasan dengan kelurahan Karwisi

\section{Populasi dan Sampel}

1. Populasi

Populasi adalah seluruh wanita usia subur yang ada di wilayah kerja Puskesmas Maccini Sawah Makassar sebanyak 5573 orang

2. Sampel

Sampel adalah yang memenuhi kriteria inklusi dan eksklusi sebanyak 100 orang

a. Kriteria Inklusi

Kriteria Inklusi adalah kriteria dimana subjek penelitian dapat mewakili sampel penelitian yang memenuhi syarat sebagai sampel.

Syaratnya yaitu:

1. Bersedia diwawacara / menjadi responden.

2. Wanita usia subur yang berkunjung di Puskesmas Maccini Sawah Makassar dalam masa penelitian.

b. Kriteria Eksklusi

Kriteria Eksklusi adalah kriteria dimana subjek penelitian tidak dapat mewakili sampel karena tidak memenuhi syarat sebagai sampel penelitian. Yang penyebabnya yaitu:

1. Subjek menolak berpartisipasi

2. Pengisian karakteristik responden tidak lengkap

3. Subjek tidak menjawab salah satu sari pertanyaan yang diberikan. (A. Aziz Alimul Hidayat, 2009, hal 69).

\section{Tekhnik pengambilan sampel (sampling)}

Pengambilan sampel pada penelitian ini dilakukan secara aksidental sampling yaitu suatu teknik penentuan berdasarkan kebetulan bertemu dengan peneliti dan apabila responden memenuhi kriteria inklusi dan eksklusi.

\section{E. Metode Pengumpulan Data}

Data yang digunakan dalam penelitian ini adalah data primer yaitu data yang diperoleh melalui pengumpulan secara langsung oleh peneliti terhadap responden menggunakan angket atau data pertanyaan yang diberikan kepada wanita usia subur di Puskesmas Maccini Sawah Makassar 2019.

\section{F. Pengololaan dan Penyajian Data}

1. Pengololan Data

Data yang diperoleh melalui pengumpulan data selanjutnya diolah secara manual menggunakan kalkulator. Dengan rumus sebagai berikut; $\mathrm{S}=\mathrm{R}$

Keterangan:

S: Skor responden

R: Jawaban yang benar (Notoatmodjo. 2007).

2. Penyajian Data

Dengan mengunakan tabel distribusi frekuensi dan presentase disertai dengan penjelasan

\section{G. Analisa data}

Data yang telah diolah selanjutnya dianalisis untuk mengetahui distribusi frekuensi atau presentase gambaran pengetahuan Wanita usia subur tentang pencegahan kanker payudara di Puskesmas Maccini Sawah Makassar tahun 2019 dengan rumus distribusi frekuensi sebagai berikut:

$$
\mathrm{P}=\frac{f}{n} x 100 \%
$$

\author{
Keterangan: \\ $\mathrm{P}$ : Presentase yang dicari \\ F : Frekuensi factor variabel \\ n : Jumlah sampel (Sugiyono, 2005)
}

\section{HASIL DAN PEMBAHASAN}

\section{A. Hasil Penelitian}

Dari hasil penelitian pada 100 responden mengenai pengetahuan wanita usia subur tentang pencegahan kanker payudara di Puskesmas Maccini Sawah Makassar tahun 2019, diperoleh hasil penelitian yang disajikan dalam bentuk tabel distribusi frekuensi berikut ini:

Tabel I. Distribusi Frekuensi Tingkat Pengetahuan Wanita Usia Subur Tentang Pengertian Kanker Payudara di Puskesmas Maccini Sawah Makassar Tahun 2019

\begin{tabular}{ccc}
\hline $\begin{array}{c}\text { Tingkat } \\
\text { Pengetahuan }\end{array}$ & Frekuensi & $\begin{array}{c}\text { Presentase } \\
(\%)\end{array}$ \\
\hline Tahu & 68 & 68 \\
Tidak Tahu & 32 & 32 \\
\hline Jumlah & 100 & 100 \\
\hline
\end{tabular}

Sumber: Hasil pengolahan data primer

Berdasarkan tabel I menunjukkan lebih banyak yang tahu tentang pengertian kanker payudara yaitu sebanyak 68 orang $(68 \%)$.

Tabel II. Distribusi Frekuensi Tingkat Pengetahuan Wanita Usia Subur Tentang Faktor Resiko Kanker Payudara di Puskesmas Maccini Sawah Makassar Tahun 2019

Tingkat Frekuensi Presentase




\begin{tabular}{|c|c|c|}
\hline Pengetahuan & & $(\%)$ \\
\hline Tahu & 43 & 43 \\
\hline Tidak Tahu & 57 & 57 \\
\hline Jumlah & 100 & 100 \\
\hline
\end{tabular}

Berdasarkan tabel II di atas menunjukkan lebih banyak yang tidak tahu tentang faktor resiko kanker payudara yaitu 57 orang (57\%).

Tabel III. Distribusi Frekuensi Tingkat Pengetahuan Wanita Usia Subur Tentang Gejala Kanker Payudara di Puskesmas Maccini Sawah Makassar Tahun 2019

\begin{tabular}{ccc}
\hline $\begin{array}{c}\text { Tingkat } \\
\text { Pengetahuan }\end{array}$ & Frekuensi & $\begin{array}{c}\text { Presentase } \\
(\boldsymbol{\%})\end{array}$ \\
\hline Tahu & 64 & 64 \\
Tidak Tahu & 36 & 36 \\
\hline Jumlah & 100 & 100 \\
\hline
\end{tabular}

Sumber: Hasil pengolahan data primer

Berdasarkan tabel III menunjukkan lebih banyak yang tahu tentang gejala kanker payudara yaitu sebanyak 64 orang $(64 \%)$.

Tabel IV. Distribusi Frekuensi Tingkat Pengetahuan Wanita Usia Subur Tentang Pencegahan Kanker Payudara di Puskesmas Maccini Sawah Makassar Tahun 2019

\begin{tabular}{ccc}
\hline $\begin{array}{c}\text { Tingkat } \\
\text { Pengetahuan }\end{array}$ & Frekuensi & $\begin{array}{c}\text { Presentase } \\
(\%)\end{array}$ \\
\hline Tahu & 74 & 74 \\
Tidak Tahu & 26 & 26 \\
\hline Jumlah & 100 & 100
\end{tabular}

Sumber: Hasil pengolahan data primer

Berdasarkan tabel IV menunjukkan lebih banyak yang tahu tentang pencegahan kanker payudara yaitu sebanyak 74 orang $(74 \%)$

Tabel V. Distribusi Frekuensi Tingkat Pengetahuan Wanita Usia Subur Tentang Pemeriksaan Payudara Sendiri (SADARI) di Puskesmas Maccini

\begin{tabular}{ccl}
\hline $\begin{array}{c}\text { Tingkat } \\
\text { Pengetahuan }\end{array}$ & Frekuensi & Presentase (\%) \\
\hline Tahu & 55 & 55 \\
Tidak Tahu & 45 & 45 \\
\hline Jumlah & 100 & 100 \\
\hline
\end{tabular}

Sumber: Hasil pengolahan data primer

Berdasarkan tabel V di atas menunjukkan lebih banyak yang tahu tentang pemeriksaan payudara sendiri (SADARI) yaitu sebanyak 55 orang $(55 \%)$.

\section{B. Pembahasan}

Populasi pada penelitian ini adalah seluruh wanita usia subur di wilayah kerja Puskesmas Maccini Sawah yang berjumlah 5573 orang, dan sampel yang diambil pada penelitian ini adalah 100 orang berdasarkan jumlah wanita usia subur yang berkunjung di Puskesmas Maccini Sawah pada saat penelitian. Jumlah sampel pada penelitian ini sangat sedikit tidak sesuai dengan banyaknya populasi wanita usia subur pada wilayah kerja Puskesmas Maccini Sawah oleh karena terbatasnya waktu penelitian dan sedikitnya wanita usia subur yang berkunjung ke Puskesmas Maccini Sawah pada saat penelitian.

Berdasarkan hasil penelitian di atas, maka peneliti mencoba membahas Pengetahuan Wanita Usia Subur Tentang Pencegahan Kanker Payudara ditinjau dari berbagai komponen dikaitkan dengan berbagai referensi yang ada:

1. Pengetahuan Wanita Usia Subur Tentang Pengertian Kanker Payudara

Berdasarkan tabel I, dapat dilihat dari 100 responden, sebanyak 68 orang $(68 \%)$ yang tahu tentang pengertian kanker payudara, dan 32 orang $(32 \%)$ yang tidak tahu. Hal ini disebabkan karena responden yang tahu tentang pengertian kanker payudara lebih proaktif dalam merespon informasi tentang kanker payudara, dan juga aktif dalam mencari dan mengikuti penyuluhan tentang dampak dan bahaya kanker payudara tersebut.

Pengetahuan yang mereka miliki diperoleh melalui berbagai proses untuk mencari tahu suatu kebenaran dan itu semua tidak hanya didapat dari pendidikan formal saja tetapi juga dari pengalaman dengan menggunakan indera pendengaran dan indera penglihatan (Notoatmodjo, 2005 hal 50).

Teori mengatakan bahwa Pengetahuan adalah hasil penginderaan manusia atau hasil tahu seseorang terhadap objek melalui indera yang dimilikinya seperti mata, hidung telinga, dan sebagainya (Notoatmodjo, 2005, hal 50).

Walaupun hasil penelitian menunjukkan bahwa lebih banyak responden mengetahui tentang pengertian kanker payudara tetapi jumlah responden dalam penelitian ini masih sedikit maka kita tidak bisa mengambil kesimpulan bahwa seluruh wanita usia subur di Puskesmas Maccini Sawah mengetahui tentang pengertian kanker payudara.

2. Pengetahuan Wanita Usia Subur Tentang Faktor Resiko Kanker Payudara

Berdasarkan tabel II, dapat dilihat dari 100 responden, sebanyak 43 orang (43\%) yang tahu tentang faktor resiko kanker payudara, dan 57 orang (57\%) yang tidak tahu. Hal ini disebabkan karena kurangnya informasi yang diperoleh responden tentang faktor resiko dan tidak adanya kesadaran individual untuk 
mencari informasi dan mengetahui lebih jauh tentang faktor resiko apa saja yang menyebabkan seseorang menderita kanker payudara.

Oleh sebab itu maka perlu diberikan penyuluhan atau sosialisai kepada masyarakat tentang faktor resiko yang menyebabkan kanker payudara.

3. Pengetahuan Wanita Usia Subur Tentang Gejala Kanker Payudara

Berdasarkan tabel III, dapat dilihat dari 100 responden, sebanyak 64 orang $(64 \%)$ yang tahu tentang gejala kanker payudara, dan 36 orang (36\%) yang tidak tahu. Hal ini disebabkan karena responden yang tahutentang gejala kanker payudara punya pemahaman yang lebih, aktif mencari informasi, pernah mendengarkan tentang gejala kanker payudara, dan aktif dalam setiap penyuluhan yang dilaksanakan oleh petugas kesehatan.

Sama halnya dengan penjelasan sebelumnya yang menyatakan bahwa pengetahuan diperoleh melalui berbagai proses untuk mencari tahu suatu kebenaran dan itu semua tidak hanya didapat dari pendidikan formal saja tetapi juga dari pengalaman dengan menggunakan indera pendengaran dan indera penglihatan. (Soekidjo Notoatmodjo, 2005, hal 50).

Walaupun hasil penelitian menunjukkan bahwa lebih banyak responden mengetahui tentang gejala kanker payudara tetapi jumlah responden dalam penelitian ini masih sedikit maka kita tidak bisa mengambil kesimpulan bahwa seluruh wanita usia subur di Puskesmas Maccini Sawah mengetahui tentang gejala kanker payudara.

4. Pengetahuan Tentang Pencegahan Kanker Payudara

Berdasarkan tabel IV, dapat dilihat dari 100 responden, sebanyak 74 orang $(74 \%)$ yang tahu tentang pencegahan kanker payudara, dan 26 orang (26\%) yang tidak tahu. Hal ini disebabkan karena responden pernah mendengarkan tentang pencegahan kanker payudara, dan sadar tentang bahayanya, sehingga pencegahan itu lebih didahulukan. Disamping itu adanya bukti-bukti dari orang yang pernah atau sementara mengidap penyakit kanker payudara tersebut maka responden lebih dominan untuk mengetahui pencegahan kanker payudara.

Sama halnya dengan penjelasan sebelumnya yang menyatakan bahwa pengetahuan diperoleh melalui berbagai proses untuk mencari tahu suatu kebenaran dan itu semua tidak hanya didapat dari pendidikan formal sajatetapi juga dari pengalaman dengan menggunakan indera pendengaran dan indera penglihatan (Notoatmodjo, 2005, hal 50).
Walaupun hasil penelitian menunjukkan bahwa lebih banyak responden mengetahui tentang pencegahan kanker payudara tetapi jumlah responden dalam penelitian ini masih sedikit maka kita tidak bisa mengambil kesimpulan bahwa seluruh wanita usia subur di Puskesmas Maccini Sawah mengetahui tentang pencegahan kanker payudara.

5. Pengetahuan Tentang Pemeriksaan Payudara Sendiri

Berdasarkan tabel $\mathrm{V}$ di atas, dapat dilihat dari 100 responden, sebanyak 55 orang $(55 \%)$ yang tahu tentang pemeriksaan payudara sendiri (SADARI), dan 45 orang (45\%) yang tidak tahu. Hal ini disebabkan karena responden pernah mendengarkan pemeriksaan payudara sendiri yang sifatnya lebih mudah. sehingga pengetahuan tentang pemeriksaan payudara sendiri lebih dimengerti dikalangan masyarakat, disamping pengetahuan yang didapat dari pengalaman pribadi dan informasi dari luar.

Sama halnya dengan penjelasan sebelumnya yang menyatakan bahwa pengetahuan diperoleh melalui berbagai proses untuk mencari tahu suatu kebenaran dan itu semua tidak hanya didapat dari pendidikan formal saja tetapi juga dari pengalaman dengan menggunakan indera pendengaran dan indera penglihatan. (Soekidjo Notoatmodjo, 2005, hal $50)$.

Walaupun hasil penelitian menunjukkan bahwa lebih banyak responden mengetahui tentang pemeriksaan payudara sendiri tetapi jumlah responden dalam penelitian ini masih sedikit maka kita tidak bisa mengambil kesimpulan bahwa seluruh wanita usia subur di Puskesmas Maccini Sawah mengetahui tentang pemeriksaan payudara sendiri.

\section{PENUTUP}

\section{A. Kesimpulan}

1. Populasi pada penelitian ini adalah seluruh wanita usia subur di wilayah kerja Puskesmas Maccini Sawah yang berjumlah 5573 orang, dan sampel yang diambil pada penelitian ini adalah 100 orang berdasarkan jumlah wanita usia subur yang berkunjung di Puskesmas Maccini Sawah pada saat penelitian. Jumlah sampel pada penelitian ini sangat sedikit tidak sesuai dengan banyaknya populasi wanita usia subur pada wilayah kerja Puskesmas Maccini Sawah oleh karena terbatasnya waktu penelitian dan sedikitnya wanita usia subur yang berkunjung ke Puskesmas Maccini Sawah pada saat penelitian.

2. Berdasarkan penelitian yang dilakukan pada 100 wanita usia subur tentang pengertian 
kanker payudara, gejala kanker payudara, pencegahan kanker payudara dan pemeriksaan payudara sendiri di Puskesmas Maccini Sawah Makassar 2019 dalam kategori baik. Tetapi masih perlu ditambah jumlah responden dalam penelitian ini mengingat populasi wanita usia subur di wilayah kerja Puskesmas Maccini Sawah sangat banyak dan sampel pada penelitian ini tidak bisa mewakili seluruh populasi.

3. Berdasakan penelitian yang dilakukan pada wanita usia subur tentang faktor resiko kanker payudara di Puskesmas Maccini Sawah Makassar 2019 dalam kategori kurang baik. Hal ini disebabkan karena kurangnya informasi yang diperoleh responden tentang faktor resiko dan tidak adanya kesadaran individual untuk mencari informasi dan mengetahui lebih jauh tentang faktor resiko apa saja yang menyebabkan seseorang menderita kanker payudara.

\section{B. Saran}

Berdasarkan kesimpulan di atas dapat dikemukakan beberapa saran sebagai berikut:

1. Diharapkan kepada seluruh wanita untuk lebih memperdalam dan memperluas lagi pengetahuan tentang pencegahan kanker payudara, sehingga angka kesakitan dan kematian akibat kanker payudara dapat diminimalkan.

2. Diharapkan kepada para tenaga medis atau pakar yang bergelut di dunia pencegahan penyakit kanker payudara agar selalu memberikan arahan atau penyuluhan yang berkaitan dengan kanker payudara tersebut.

3. Diharapkan kepada seluruh wanita agar menghindari semua makanan dan minuman yang dilarang oleh Allah. Supaya kita terhindar dari segala penyakit terutama kanker payudara.

\section{DAFTAR PUSTAKA}

Benson Ralph C, Pernoll Marun L. 2009. Karsinoma Payudara, Buku Saku Obstetri Dan Genekologi. Penerbit Buku Kodekteran EGC, Jakarta. Hal 491-494

Djalali Dr. 2009. Teori Kognitif, Psikologi Pendidikan. Bumi Aksara. Jakarta. Hal 77.

Hidayat Alimul Aziz. 2007. Menentukan Populasi, Sampel, Dan Tehnik Sampling, Metode Penelitian Tehnik Analisa Data. Salemba Medika, Jakarta. Hal 51 dan 69.

Nurcahyo Jalu. 2010. Mengenal Kanker Payudara, Awas Bahaya Kanker Payudara: Mengenal,
Mencegah, dan Mengobati Sejak Dini Dua Kanker Pembunuh Paling Ditakuti Wanita. Yohana Totalitas Publisher, Yogyakarta. Hal 94, 98-102, 108-114.

Notoatmodjo Soekidjo. 2005. Promosi Kesehatan Teori Dan Aplikasinya. PT Rineka Cipta, Jakarta. Hal 50.

Parwiroharjo sarwono. 2005. Kelainan Pada Payudara, Ilmu Kandungan. Yayasan Bina Pustaka, Jakarta. Hal 486-493.

Purnomo Heru. 2009. Mengenal, Mengenal, Mendignosa, Dan Penyembuhan Kanker Payudara, Penyakit Yang Paling Mematikan: Pencegahan Dan Pengobatan. Buana pustaka, Yogyakarta. Hal 91, 95-97, 106-107.

Purwoastuti Th Endang. 2008. Kanker Payudara, Kanker Payudara: Pencegahan dan Deteksi Dini. Kanisius, Yogyakarta. Hal 13-18, 22-28.

Setiati Eni. 2009. Kanker Payudara Pembunuh Nomor Dua Wanita, Waspadai 4 Kanker Ganas Pembunuh Wanita. C.V Andi Offset, Yogyakarta. Hal 42-43.

Sukmawati. 2015. Kanker Serviks dan Payudara Terbanyak di Sulawesi Selatan. Tempo. Makassar. Data Diakses tanggal 25 maret 2015 